Mathematical Problems of Computer Science 54, 108--115, 2020.

UDC 004.93

\title{
A Rational Approach to the Problem of Accurate UAV Landing Using Intelligent Image Processing Methods
}

\author{
David G. Asatryan, Vardan V. Kurkchiyan and Grigor S. Sazhumyan \\ Institute for Informatics and Automation Problems of NAS RA \\ e-mail: dasat@iiap.sci.am, vakur87@gmail.com,grigorsazhumyan@gmail.com
}

\begin{abstract}
This paper is devoted to the description of preliminary results of solving two problems related to the problem of accurate unmanned aerial vehicle (UAV) landing. The first task is to develop a methodology for rational choice of the landing platform image, which ensures the best recognition by an UAV from any angle and a reasonable observation distance. The second task is to develop a procedure for a sequential analysis of the current situation, forthcoming of the UAV to the platform and accurate landing. To solve these problems, it is proposed to use the previously developed intelligent processing methods based on the using of the structural properties of an image. In particular, the technique is applied using the Weibull distribution model for the gradient magnitude of an image and its components. Numerical results are presented that show the prospects of the proposed procedures and the directions for improving the developed techniques.
\end{abstract}

Keywords: UAV, Landing, platform, image structural properties, similarity measure, image orientation.

\section{Introduction}

Currently, small unmanned aerial vehicles (UAVs) are widely used in solving many tasks: search, rescue, environmental monitoring, surveillance, inspection, etc. With the help of UAVs, it is easy to access almost any environment. As it is well known, for UAV navigation systems of global positioning GPS or GLONASS and other technical and communication means are widely used.

One of the main problems in the development of effective systems using UAVs is to ensure accurate automatic landing of an unmanned aerial vehicle on a specific landing platform.

*This work was supported by the RA Science Committee in the frames of the research project SCS 20DP-2B01. 
However, it is generally accepted that the use of a global positioning system GPS or GLONASS does not provide the required landing accuracy, especially during the last stage of landing. Therefore, in order to solve this problem, it is inevitable to involve artificial intelligence methods based on modern computer vision systems and mathematical image processing. Therefore, studies of the possibilities of autonomous navigation of UAVs using the above mentioned methods are intensively carried out both in Russia [1] and abroad [2].

The solution of the problem of precise landing under consideration, in turn, consists of several independent tasks based on the rational use of various intelligent image processing methods with or without the use of information from GPS. So, in [3], it was proposed to use infrared cameras, an algorithm for recognizing infrared landmarks was built and tested at the stand. In [4], an algorithm is proposed for extracting the runway boundary lines using the Hough transform and estimating the position, lateral offset of UAV with respect to the runway center line. In [5], a solution for high-precision landing based on the use of ArUco markers is presented. In the proposed solution, a UAV equipped with a low-cost camera is able to detect ArUco markers sized 56 x $56 \mathrm{~cm}$ from an altitude of up to $30 \mathrm{~m}$. In the review work [6], a comparative analysis of a number of UAV landing methods with or without GPS was carried out.

However, these and many other similar works do not consider in sufficient detail the influence of interfering factors on the accuracy of landing. Therefore, it becomes relevant to use methods that are sufficiently stable against such factors.

In this paper, we consider only two problems that inevitably arise in the development of any autonomous UAV landing system based on the use of video material. The first task is to develop a methodology for the rational choice of an image of the landing platform, which provides better recognition by a UAV from any angle and a reasonable distance of observation by the aircraft. The second task is more complex and consists in developing a procedure for sequential analysis of the situation when approaching the platform and final landing.

This work is devoted to the description of the preliminary results of solving these problems using the previously developed intellectual methods based on the use of the structural properties of the image.

\section{Processing Technique}

The processing technique is based on the use of a Weibull distribution model for the magnitude of the image gradient. The method for estimating model parameters $\eta>0$ (shape parameter) and $\lambda>0$ (scale parameter) and their use in image processing tasks is described in [7-13]. Let us recall the working formulas proposed for estimating the proximity of two images and the angle of the orientation of the image. Thus, the formula for estimating the proximity of two images has the form

$$
W^{2}=\frac{\min \left(\eta_{1}, \eta_{2}\right) \min \left(\lambda_{1}, \lambda_{2}\right)}{\max \left(\eta_{1}, \eta_{2}\right) \max \left(\lambda_{1}, \lambda_{2}\right)}, 0<W^{2} \leq 1,
$$

and the estimation of the angle of an image orientation is based on the formula as follows:

$$
\operatorname{tg} \alpha=\frac{2 * \sigma_{H} \sigma_{V} \rho_{H V}}{\sigma_{H}^{2}-\sigma_{V}^{2}-\sqrt{\left(\sigma_{H}^{2}-\sigma_{V}^{2}\right)^{2}+4 \sigma_{H}^{2} \sigma_{V}^{2} \rho_{H V}^{2}}},
$$

where $\mu_{H}, \mu_{V}, \sigma_{H}, \sigma_{V}$ are the means and standard deviations of the gradient components $\left(G_{V}, G_{H}\right)$, and $\rho_{H V}$ is the correlation coefficient between the components. All these values are estimated from the set of gradient components calculated using the Sobel operator. 


\section{Methodology for Selecting Pictures for the Landing Platform}

As noted above, as a basis for the implementation of this group of problems, it is advisable to use artificial intelligence methods based on the modern intellectual methods of mathematical image processing. The main obstacle for the successful solution of the problems under consideration is the variability (non-repeatability) of the content of the frames of the video sequence captured by the UAV camera during flight, which arises due to the change in the angle and coordinates of the $\mathrm{UAV}$ at each moment of time, the influence of numerous interferences and distorting factors imposed on the image of the scene being shot, etc. Therefore, the paper proposes to use the methods described in the previous paragraph of this paper, which have certain properties of stability with respect to these factors.

The task here is to reliably detect and recognize the landing platform, on which a certain image is applied, which stands out quite clearly against the background of the surrounding space. At the same time, from the point of view of recognition and noise immunity, the content and structure of this image are very important, therefore, in order to select a suitable landing platform for a UAV, it is necessary to perform a certain study of its types and structure.

The proposed technique is based on the Weibullian model of the gradient magnitude and uses a statistical estimate of the distribution parameters and image orientation angle from the corresponding empirical distribution. For brevity, we will omit the details described in sufficient detail in the cited publications.

Application of the proposed technique to various types of images used in the available literature on UAVs made it possible to focus on images containing the simplest elements of the same type. To illustrate the calculation results, we give an example. Table 1 lists three sample landing platform images and our proposed custom structure sample. The foreshortening of these images was transformed in an imaginary situation of observation by a UAV camera at different angles by means of modeling, performing image rotations by 10, 20 and 30 degrees, as well as changing its width to $75 \%$ of its original size. The images obtained in this way were compared for similarity with the original using the measure $\mathrm{W}^{2}$.

Table 1. Results of the samples testing for using on the landing platform.

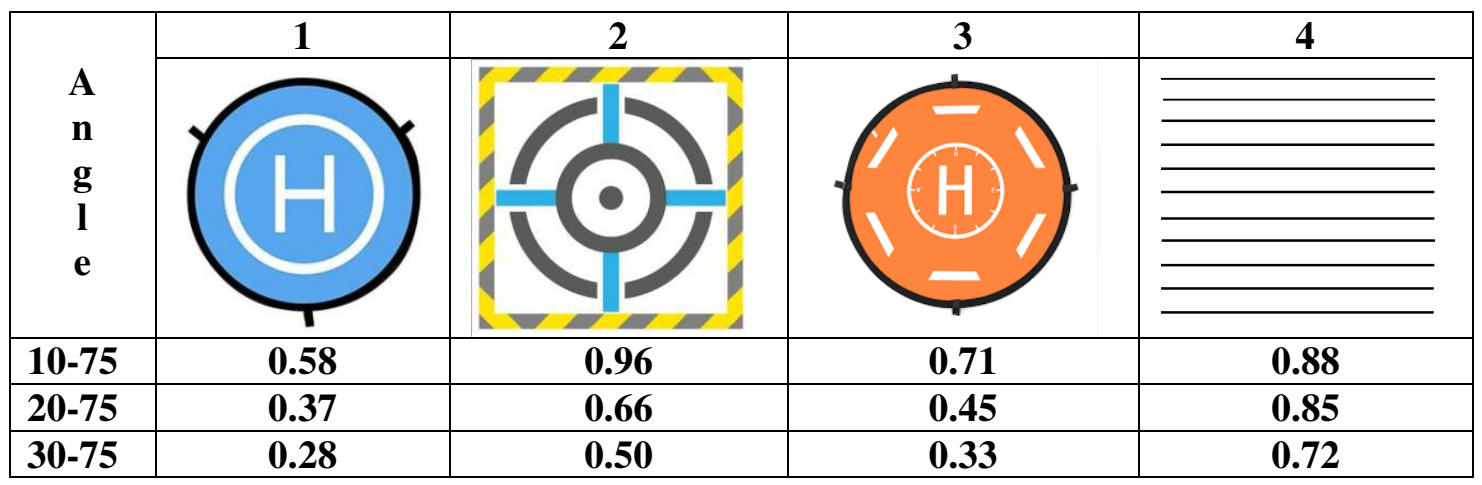

The results of the analysis of the data in Table 1 show that image 4 has the greatest resistance to changing the angle, and image 2 takes the second place. However, we prefer image 4, since it has a clearly expressed and confidently estimated dominant direction, which is very important when the correction algorithm works for the movement of the UAV at searching the landing platform and approaching it.

Thus, the proposed procedure can be used as a tool for the rational choice of the landing platform image. 


\section{Algorithm for the Search of the Landing Platform and for UAV Landing}

The most important operation of the system is the search of a landing platform and ensuring a sufficiently accurate and smooth landing of the UAV on this platform to perform the envisaged work on recharging its batteries. In this case, it is assumed that the UAV has reached a zone of terrain, in which the image of the platform is available from a certain angle and distance, using standard navigation or other equipment. Further actions to search for a platform are carried out using exclusively information delivered by UAV on-board equipment.

The tasks to be solved when searching for a platform and managing the landing process are as follows.

- Pre-processing of the image in the frame of the video sequence, by definition, required parameters, filtering, etc.;

- Establishment of the fact of presence and the selection of the corresponding area of the platform image on the current frame of the video sequence;

- Recognition and selection of the image of the platform image from the selected area, evaluation of its parameters;

- Elaboration of a solution for adjusting the UAV's course to forthcoming to the platform.

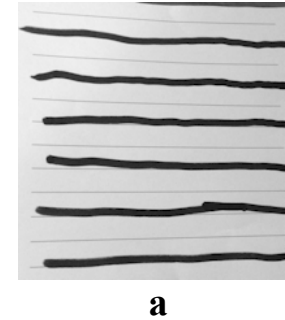

a

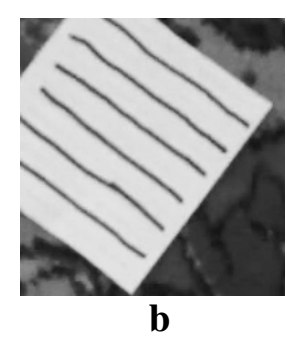

b

Fig. 1. An example of a platform image (a) and the selected segment which is similar to the platform image (b).

Here's an example to illustrate the current step of the above procedure. Figure 1a shows an example of a platform image plotted on a terrain scene. Fig. 2a shows the next frame of the video sequence containing the image of the platform captured from a certain angle. The procedure for finding a scene area similar to the pattern shown in Fig. 1a is performed by calculating its proximity to the image selected using the sliding window procedure (see also [10]). The found area, most similar to the sample, is shown in Fig. 1b (marked in a colored box). Note that the proximity of these images is PSNR $=8.12 \mathrm{~dB}$ (negligible, which is to be expected from the rootmean-square measure), and $\mathrm{W}^{2}=0.7$ (quite acceptable!). As calculations by the method [13] show, the orientation angle of the found area is $-39.5^{\circ}$. This result gives grounds to develop a command to turn the UAV to the left by $+39.5^{\circ}$ and change the flight altitude by a certain amount, approaching the platform. 


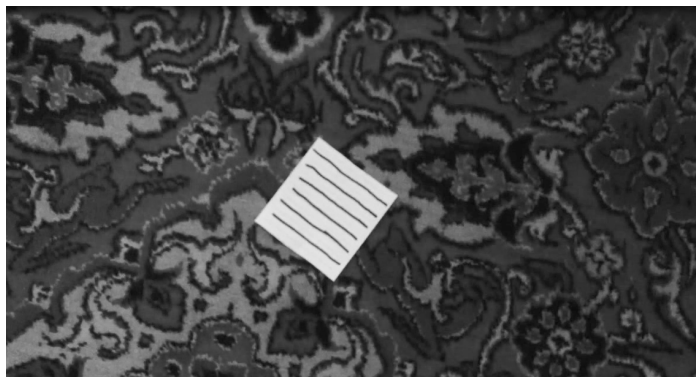

a. Next frame in the video

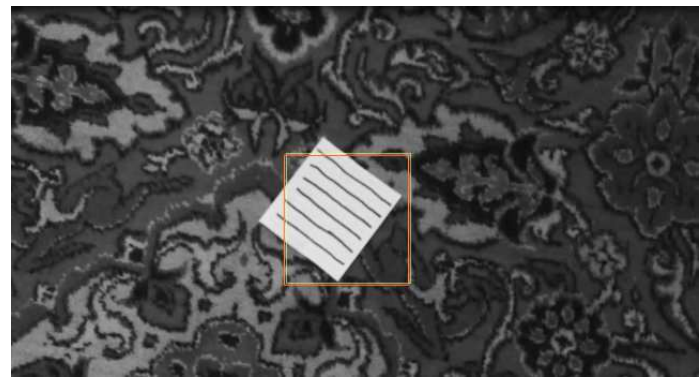

b. Found segment

Fig. 2. Searching and finding the area of the image that is most similar to the platform.

An example of the image that will be available to the UAV in the new position is shown in Fig. 3. It is clear that the new section of the platform with a new perspective will be more similar to the "reference" image of the platform $\left(\mathrm{W}^{2}=0.8\right)$. After that, the procedure is repeated until the UAV "sits" on the platform.

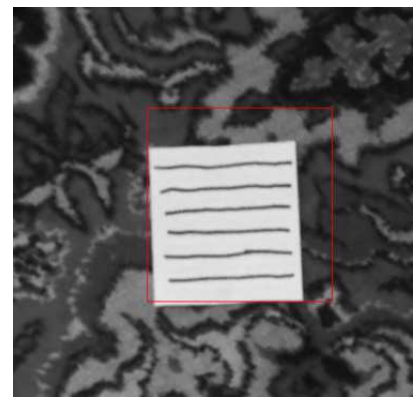

Fig. 3. Image of a new scene after turning and changing the UAV flight altitude.

The described experiments and the given numerical results show the prospects of the proposed procedures and reveal the directions for improving the developed methods.

\section{Conclusions}

The article briefly describes the preliminary results of solving two problems related to the problem of accurate UAV landing. The first task is to develop a methodology for the rational choice of the landing platform image, which ensures the best recognition by an unmanned aerial vehicle from any angle and a reasonable observation distance. It is shown that from the recognition point of view and noise immunity it is advisable to use images containing a structure with the simplest elements of the same type. The second task is to develop a procedure for the sequential analysis of the current situation, the approach of the UAV to the platform and accurate landing. The solution of these problems is carried out using a previously developed technique using the Weibull distribution model for the magnitude of the image gradient and its 
components. Numerical results are presented that show the prospects of the proposed procedures and the directions for improving the developed techniques.

\section{References}

[1] А. Е. Косова, А. М. Кориков, “Автоматическая посадка малых беспилотных летательных аппаратов с использованием компьютерного зрения”, Доклады ТУСУР том 20, № 3, cc.191-196, 2017.

[2] D. Scaramuzza, S. Weiss and R. Siegwart, "MAV navigation through indoor corridors using optical flow", Robotics and Automation (ICRA) - IEEE International Conference on (Anchorage, AK, USA), pp. 3361-3368, 2010.

[3] К. В. Иванников, А. В. Гаврилов, А. С. Боев, И. С. Шошиню Способ посадки беспилотного летательного аппарата вертолетного типа с использованием инфракрасной камеры. Вестник Кониерна ВКО «Алмаз - Антей», № 3, с. 67-73, 2016.

[4] G. Anitha Dr. and R. N. GireeshKumar, "Vision based autonomous landing of an unmanned aerial vehicle", Elsevier, Procedia Engineering, vol. 38, pp. 2250-2256, 2012.

[5] J. Wubben, F. Fabra, C. T. Calafate, T. Krzeszowski, J. M. Marquez-Barja, Juan-Carlos Cano and P. Manzoni, "Accurate Landing of Unmanned Aerial Vehicles Using Ground Pattern Recognition”, Electronics, doi:10.3390/electronics8121532, vol. 8, no. 12, pp. 1-16, 2019.

[6] A. Gautam, P. B. Sujit and S. Saripalli, "A survey of autonomous landing techniques for UAVs", IEEE International Conference on Unmanned Aircraft Systems (ICUAS), pp. 12101218, 2014.

[7] D. Asatryan, K. Egiazarian, "Quality assessment measure based on image structural properties", Proc. of the International Workshop on Local and Non-Local Approximation in Image Processing, Finland, Helsinki, pp. 70-73, 2009.

[8] D. Asatryan, K. Egiazarian and V. Kurkchiyan, "Orientation estimation with applications to image analysis and registration" International Journal "Information Theories and Applications", vol. 17, no. 4, pp. 303-311, 2010. Erratum in International Journal "Information Theories and Applications", vol. 24, no. 4, p. 397, 2017.

[9] Д. Г. Асатрян, В. В. Куркчиян, Л. Р. Харатян, “Метод классификации текстур с использованием структурных характеристик изображения", Компьютерная оптика, N.3, c. 574-579, 2014.

[10] D. G. Asatryan, "Structure-based technique for object detecting in UAV imagery", Mathematical Problems of Computer Science, vol. pp. 44, 51-58, 2015.

[11] D. Asatryan, S. Hovsepyan and V. Kurkchiyan, "Road tracking from UAV imagery using gradient information", International Journal "Information Technologies \& Knowledge", vol. 10, no. 2, pp. 191-199, 2016.

[12] D. G. Asatryan, "Image blur estimation using gradient field analysis", [In Russian]. Computer Optics, vol. 41, no. 6, pp. 957-962, 2017. http://computeroptics.smr.ru/KO/PDF/KO41-6/410622.pdf

[13] D. G. Asatryan, "Gradient-based technique for image structural analysis and applications", Computer Optics, DOI: 10.18287/2412-6179-2019-43-2-245-250. vol. 43, no. 2, pp. 245$250,2019$.

Submitted 12.07.20, accepted 20.10.20. 


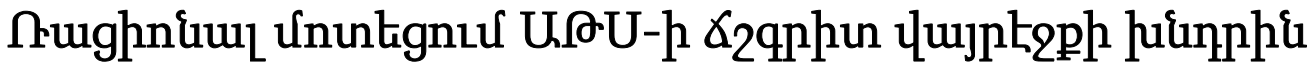

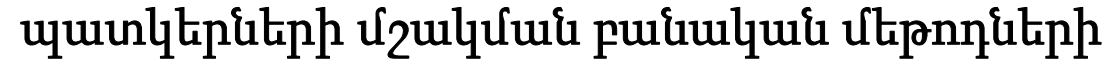 पhpunuture
}

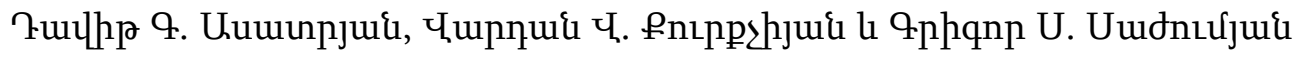

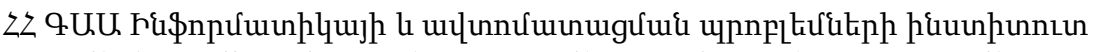 \\ e-mail: dasat@iiap.sci.am,vakur87@gmail.com, grigorsazhumyan@gmail.com
}

\section{Uরựnนุnıu}

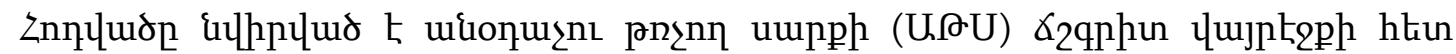

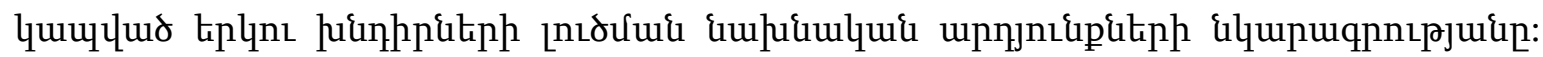

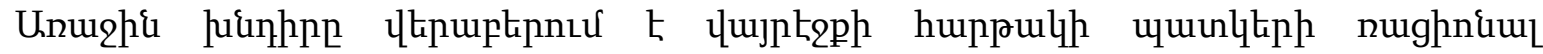

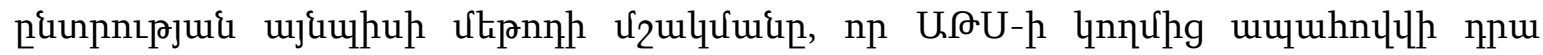

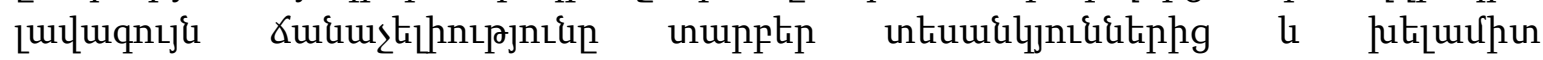

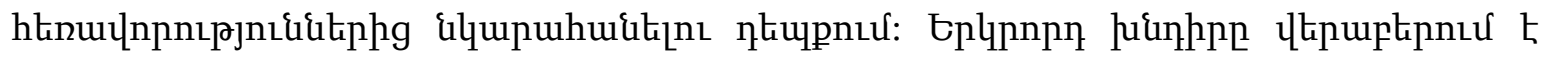

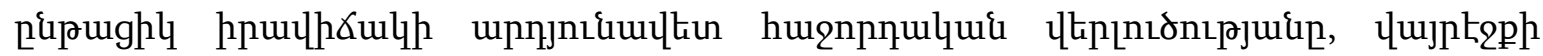

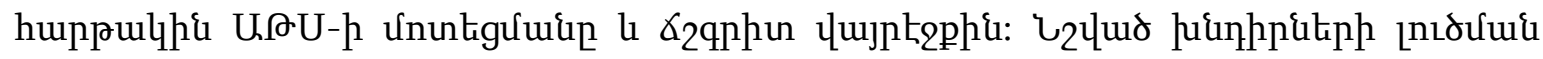

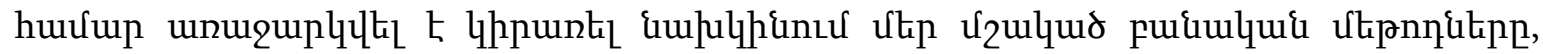

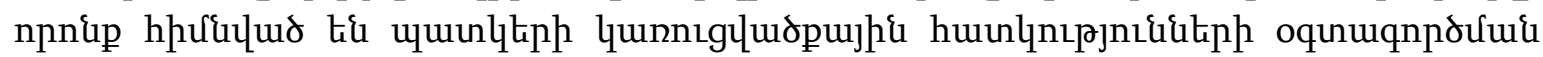

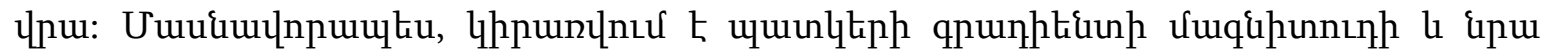

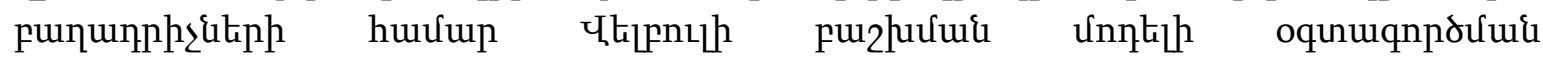

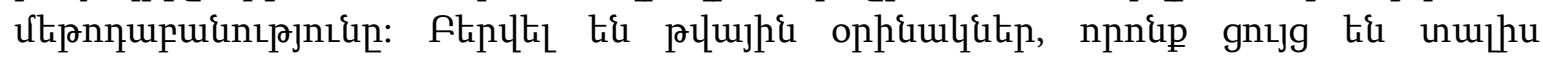

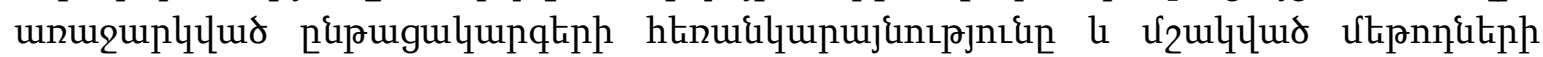

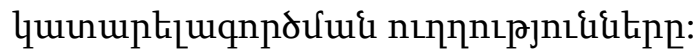

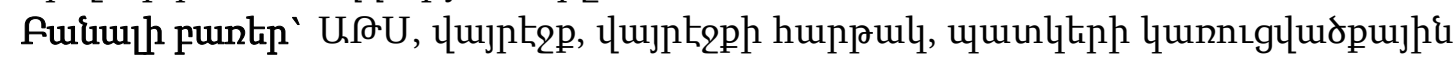

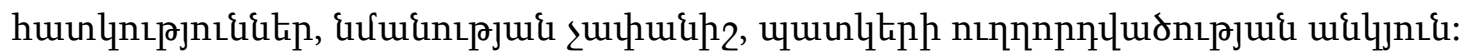




\title{
Рациональный подход к проблеме точного приземления БЛА с применением интеллектуальных методов обработки изображений
}

\author{
Давид Г. Асатрян, Вардан В. Куркчиян и Григор С. Сажумян \\ Институт проблем информатики и автоматизации НАН РА \\ e-mail: dasat@iiap.sci.am, vakur87@gmail.com, grigorsazhumyan@gmail.com
}

\begin{abstract}
Аннотация
Статья посвящена описанию предварительных результатов решения двух задач, связанных с проблемой точного приземления беспилотного летательного аппарата (БЛА). Первая задача - разработка методики рационального выбора изображения посадочной платформы, обеспечивающего лучшую узнаваемость из любого ракурса и разумного расстояния наблюдения БЛА. Вторая задача состоит в разработке эффективной процедуры последовательного анализа текущей ситуации, приближения БЛА к платформе и точного приземления. Для решения указанных задач предлагается использовать разработанные нами ранее интеллектуальные методы обработки, основанные на использовании структурных свойств изображения. В частности, применяется методика с использованием модели распределения Вейбулла для магнитуды градиента изображения и его компонент. Приведены численные результаты, показывающие перспективность предложенных процедур и направления совершенствования разработанных методик.

Ключевые слова: БЛА, приземление, посадочная платформа, структурные свойства изображения, мера сходства, преимущественное направление изображения
\end{abstract}

